\title{
ФРАГМЕНТАЦИЯ ЕВРОПЕЙСКОГО ОБЩЕСТВА: ОСОБЕННОСТИ КУЛЬТУРНОГО И РЕЛИГИОЗНОГО МНОГООБРАЗИЯ
}

\begin{abstract}
Аннотация. Статья посвящена взаимосвязям европейского сочиума с этническими меньшинствами, придерживаюшимися своих культурных и конфессиональных традиций и обычаев. В ней рассматриваются этнокультурные сдвиги, вызванные ростом миграционных потоков. Анализируются особенности интеграџионной политики отдельных стран Европейского союза, недостатки основных моделей интеграции, обусловившие необходимость перехода к новым альтернативным вариантам. Выделяются новые элементы взаимодействия культур и создание новых форм инокультурной идентичности мусульман - мигрантов внутри европейского социума. Даётся оценка последствий возможного разрастания диаспор и влияния сочиокультурной экспансии этнических меньшинств на принимающее общество и углубление в нём разногласий и неравенства. Рассматриваются проблемы фрагментации европейского общества, «исламизачии» европейских стран и новые подходы по сближению разных этносов и культур, способствующих новой модели организации межкультурного взаимодействия в странах ЕС.
\end{abstract}

Ключевые слова: интеграция мигрантов-мусульман, Европейский союз, межэтническое взаимодействие и конфликты, национальная идентичность, ислам.

Культурное и религиозное многообразие в европейском обществе связано с миграцией в Европу, представляющей сложное переплетение демографических, экономических, политических, социально-культурных и конфессиональных проблем, на которые оказывают влияние процессы глобализации и интеграции. Миграционные процессы разнообразны как в количественном измерении, так и по качественным характеристикам: по этническому составу, цивилизационной и культурно-конфессиональной составляющей. Они усиливают дезинтеграцию принимающих обществ, ведут к размыванию их национальной идентичности и нарастанию этно-конфессиональных противоречий, возникновению компактно проживающих этнических групп, которые, как правило, не интегрируются в социальнокультурное пространство европейских стран. Проблема идентичности современной Европы связана также с кризисом христианства и постепенным ослаблением его как идентификационной стратегии европейцев.

\section{Структурные и культурно-конфессиональные сдвиги в миграционных потоках}

В настоящее время главным цивилизационным вызовом в странах ЕС является столкновение двух культур и религий - христианства и ислама, двух цивилизаций европейской и мусульманской. Мусульманский фактор - достаточно новое явление для европейских стран, которые до массового притока мигрантов и беженцев отличались

\footnotetext{
(C) Трофимова Ольга Ефимовна - кандидат экономических наук, ведущий научный сотрудник Центра европейских исследований Национального исследовательского института мировой экономики и международных отношений им. Е.М. Примакова РАН. Aдрес: 117997, Россия, Москва, ул. Профсоюзная, д. 23. E-mail: olgatrofimova53@mail.ru.
}

DOI: http://dx.doi.org/10.15211/vestnikieran42019104110 
этнической, культурной и конфессиональной однородностью. По данным Pew Research Center (США), численность мусульман в странах Европы (ЕС, Швейцария и Норвегия) выросла с 19,5 млн чел. в 2010 г. до 25,8 млн чел. в 2016 г. и составила 4,9\% их населения, а доля немусульманского населения уменьшилась в 2010-2016 гг. на 1,7 млн чел. По прогнозам центра, численность мусульман в Европе может увеличиться в 2-3 раза к 2050 г. за счёт высоких темпов рождаемости и сохранения притока новых мигрантов и беженцев (на 7,8\% при нулевой миграции, до 11,2\% при среднем варианте миграции и до 14\% при высоких темпах миграции). По последнему сценарию в Швеции численность мусульман достигнет $30 \%$ населения страны, в Австрии 19,9\%, в Германии 19,7\%, во Франции 18\%, в Великобритании $17,2 \%{ }^{1}$. Несмотря на прогнозы, мусуль-мане пока не станут доминирующими в населении стран ЕС, но их влияние по всем направлениям усилится, как и разногласия с коренными европейцами на экономической и религиозной почве.

Рост числа мусульман в Европе способствовал усилению противоречий между консервативными ценностями ислама и либеральными европейскими традициями. Однако мусульмане постепенно приспособились жить в обществе немусульманского большинства, замыкаясь в рамках своих этнических общин. Все европейские государства признают свободу вероисповедания, но для них характерно разделение функций государства и религии, а такое положение дел прямо противоречит принципам ислама о единстве религии и государства. В итоге это приводит к тому, что мусульмане становятся наиболее отвергаемой «второстепенной нацией», возникают трения и конфликты между коренным и мусульманским населением, что представляет угрозу безопасности в Европе.

Традиционная этническая миграция из третьих стран, в основном мусульманских, постепенно сменила поток мигрантов из стран Южной Европы как Португалия, Испания, Италия, Греция, а затем из стран Центральной и Восточной Европы, Прибалтики и балканских государств после последнего расширения ЕС и стала сейчас преобладающей в Евросоюзе. В последние годы она привнесла изменения в этническую, лингвистическую, культурную и конфессиональную идентичность принимающих европейских государств. Внутриевропейская миграция остаётся незначительной по численности (4\% населения), но важной по своему значению и не нарушает культурно-конфессиональное пространство в Европе: это мигранты из «старых стран» ЕС и новых государств-членов.

Первоначально трудовые мигранты, приезжали на заработки без семей и пытались интегрироваться в европейское общество, при этом религия в то время не занимала ведущее место в жизни мигрантов. Но политика «воссоединения семей», начавшаяся с середины 1970-х гг., привела к оседанию национальных меньшинств, образованию этнических диаспор в стра-нах ЕС. Семейная миграция способствовала не только росту мусульманского населения, но и усилению замкнутости его общин с сохранением своего образа жизни и традиций, законов шариата, укоренением своей культуры без социализации в принимающем обществе. Первое поколение мусульман-мигрантов придерживалось традиционных культурнорелигиозных прак-тик, что не мешало им адаптироваться в европейский социум, но последующие поколения, родившиеся уже в Европе, переформатировали их в новый вариант культурной идентичности исламских общин, консервирующей ценности и традиции своей исторической родины. В результате этно-религиозные составляющие конфликта внутри европейского общества стали преобладающими.

Фактически произошла фрагментация европейского социума, который становится всё

\footnotetext{
Europe's growing muslim population. Pew Research Center. 29.10.2017. P. 10-17. URL: http://pewresearch.org/fact/tank/2017/11/29/Europes-growing-muslim-population (дата обращения: 15.03.2019).
}

Научно-аналитический вестник ИЕ РАН, 2019, №4 
более гетерогенным, и появилось параллельное «мусульманское общество» со своей субкультурой и идеологией, что нарушило целостность этого социума и привело к размыванию его национально-культурной идентичности, к социальной маргингализации мигрантов-мусульман и их отстранению от политической жизни. Это общество не только воспроизводит свою культуру, обычаи и религию, но и способствует его обособлению и достаточно устойчиво к внешним воздействиям. К тому же либеральное законодательство стран ЕС не содержит стимулов к интеграции мусульман в принимающие общества, а программы по интеграции мигрантов неэффективны, что осложняет их адаптацию к европейским ценностям. В некоторых странах законодательство предусматривает периодическое продление вида на жительства, не даёт мигрантам, не имеющим постоянного вида на жительство или гражданства, стимула к адаптации в обществе принимающей. Так возникает «гостевая модель» пребывания и поведения, стремление жить за счёт принимающей стороны и не терять культурную связь со своей роди-ной. Но при этом происходит постепенное замещение коренного населения в отдельных нишах на рынке труда в странах ЕC, а не использование мигрантов в качестве дополнения ме-стной рабочей силы.

В начале 1990-х гг. активизировался важный фактор, объединивший европейских мусульман, - ислам, который является сейчас второй по значению религией в Европе. В Европе три категории населения исповедуют ислам: 1) население неевропейского происхождения (мигранты, беженцы, студенты), 2) дети мигрантов, родившиеся и проживающие в Евросоюзе, 3) обращённые в ислам европейцы, которые придерживаются традиционного варианта ис-лама, тогда как мусульмане по рождению, проживающие в замкнутых общинах, часто практикуют новые варианты ислама как исламизм, означающий политическую активность под эгидой религии.

Рост мусульманского населения в Европе способствовал усилению исламского фактора, особенно в тех странах, где велика доля мусульман (Франция, Великобритания, а в последние годы ФРГ, Швеция и др.). Проблемы мусульман-мигрантов всё чаще используются политическими лидерами в предвыборных кампаниях, особенно после миграционного кризиса 2015 г., и стали одной из причин роста популярности националистических и правых партий во многих странах ЕC: Национальное объединение М. Ле Пен во Франции, «Альтернатива для Германии», «Движение 5 звезд» в Италии, «Датская Народная партия», «Шведские де-мократы», партия «Йоббик» в Венгрии, «СИРИЗА» в Греции, «PODEMOS» в Испании и др.

Появление мусульманских общин сопровождалось увеличением числа мечетей, мусульманских школ и различных исламских организаций и партий. Они не многочисленны и практически не представлены в органах власти (по нескольку человек в парламентах некоторых стран и 6 депутатов в Европарламенте). Единых мусульманских организаций в отдельных странах ЕС пока нет из-за того, что исламские общины разрознены по этническому и клановому признаку. Эта ситуация в определённой степени способствует сохранению относительного равновесия двух цивилизаций и двух религий, но не останавливает процесс «ползучей исламизации» Европы. Сложившаяся в диаспорах «неблагоприятная среда» и их социальная исключённость, возрастание роли внешних исламских спонсоров, финансирующих объедине-ния мусульман в Европе, привели к усилению популярности идей радикального ислама и под-рывной деятельности террористических ячеек, совершивших серию терактов во Франция, Ве-ликобритании, Испании, Бельгии, Германии, Швеции и других странах.

\section{Политика интеграции мусульман-мигрантов в отдельных странах ЕС}


В официальном сообщении Еврокомиссии «Об иммиграции, интеграции и занятости» 2003 г. говорилось, что «успешная интеграция мигрантов - одна из основ социального сплочения общества и одновре́менно предпосылки эффективности экономики» ${ }^{1}$. Теоретически в процессе интеграции мигрантов должно происходить их превращение в составной элемент принимающего общества. С одной стороны, дешёвая рабочая сила необходима для европейской экономики из-за старения коренного населения, с другой, европейцы опасаются исламизации и культурно-конфессиональных конфликтов в обществе. Поэтому сохранение национальной идентичности и обеспечения стабильного экономического развития тесно связаны между собой.

Этнический и конфессиональный состав мусульман, проживающих в странах ЕC, разнообразен и определён как их колониальным прошлым, так и особенностями их экономического развития, изменением структуры потребностей европейского рынка труда, демографическими сдвигами, процессами развития европейской интеграции и расширения ЕС. Наибольшее число мусульман-мигрантов сконцентрировано в странах «старого ядра» ЕС и бывших колониальных метрополиях (от 5 до 10\% населения) и в меньшей степени в Южной Европе (от 1 до 4\%) и новых государствах - членах Евросоюза, которые всячески противостоят проникновению мусульман в своё общество (страны Вишеградской группы и страны Балтии), что привело к разногласиям в рамках Евросоюза по вопросам приёма беженцев и выделения квот на их размещение.

В странах ЕС существуют несколько моделей интеграции мигрантов, которые с 1990-х гг. претерпели изменения и стали сближаться: ассимиляционная модель во Франции, в которой позже появились элементы мультикультурного подхода; британская либеральная модель культурного плюрализма, предполагающая взаимное существование культур, и близкая к мультикультурализму (используется также в Нидерландах, Бельгии, Швеции) и неудавшаяся модель гастарбайтерства в Германии, которая была построена на экономической базе, но затем наметился переход к модели функциональной ассимиляции, которая подразумевает вклю-чение мигрантов в рынок труда, но «исключает их из гражданского и политического участия при отсутствии надёжного юридического статуса» ${ }^{2}$. Эта модель также используется в Австрии, Италии, Греции и частично в Дании.

Самая многочисленная мусульманская диаспора проживает во Франции $-5,7$ млн чел. $(8,8 \%)$, а по данным французских социологов - до 8 млн или 9,6\% населения страны в 2018 г. $^{3}$ Свой вклад в рост мусульманского населения внесли республиканские традиции и либеральный подход к миграции, а также закон «почвы», по которому любой родившийся на территории Франции становится её гражданином, если хотя бы один из родителей родился во Франции. Французская ассимиляционная модель строилась на равном подходе к гражданам, на культурной однородности общества и непризнании на национальном уровне этнических меньшинств. Интеграция же рассматривалась как продолжение ассимиляционного подхода и начиналась после получения гражданства. Такая эгалитарная модель предполагала ассимиля-цию мигрантов без учёта культурных, этнических и конфессиональных различий групп населения через обучение в светских школах и при условии обязательного знания языка. Она была успешна в период первой «европейской волны» миграции из Италии, Бельгии, Испании, Португалии. Но после массового притока

\footnotetext{
${ }^{1}$ Сообщение Еврокомиссии «Об иммиграции, интеграции и занятости». Июнь 2003. СОМ (2003).

2 Чернобровкин И.П. Две модели интеграции мигрантов в ФРГ: сравнительный анализ. Социально-гуманитарные знания, №7, 2015. С. 64

${ }^{3}$ Europe Muslim Population in 2018. URL: http://www.muslimpopulation.com/Europe (дата обращения: 05.03.2019). Научно-аналитический вестник ИЕ РАН, 2019, №4
} 
мусульман во Францию она стала давать сбои и по-степенно вытесняться концепцией мультикультурализма, подразумевающей сосуществование и взаимодействие различных этнических групп, культур и религий в одном социуме.

Во Франции существует более 75 «нестабильных городских зон», более 2100 мечетей и молельных домов. В основном мусульмане селятся в пригородах крупных городов (Париж, Лион, Марсель и др.). На бытовом уровне укоренение мусульман проявляется в появлении в районах их проживания кафе, ресторанов, магазинов, где продаются халяльные продукты, одежда для мусульман и исламская литература; попытках носить мусульманский платок в школу, паранджу и никаб на улице, следовать нормам шариата и т.д.

В Германии население иммигрантского происхождения долгое время считалось «иностранным», а его присутствие - отклонением от этнокультурной однородности немецкого со-циума, что способствовало образованию закрытых диаспор. До конца 1990-х гг. предполагалось, что обучение языку и посещение занятий в школе, изучение законов, истории, культуры, то есть натурализация, помогут другим этносам усвоить немецкие культурные стандарты и интегрироваться почти во все сферы принимающего общества, кроме политической, а гражданство ФРГ, которое очень сложно получить, считалось условием интеграции мигрантов.

Новая немецкая модель функциональной ассимиляции пока не располагает отлаженным механизмом интеграции мусульман-мигрантов из-за плохих социальноэкономических условий (безработица, отсутствие жилья), социокультурного отчуждения, сегрегационного подхода при получении гражданства. В последние годы большое внимание уделяется культурно-социальной интеграции мусульман. В 2002 г. был учреждён «Европейско-исламский диалог», а в 2010-2012 гг. был разработан национальный план действий по интеграции, ставший обязательной и долгосрочной задачей для всех государственных институтов. Однако межкультурное взаимодействие после миграционного кризиса 2015 г. и роста притока беженцев и нелегалов столкнулось с такими проблемами, как проявление религиозной нетерпимости и ксенофобии, рост преступности среди мигрантов.

В Великобритании модель интеграции мусульман основывается на либерально-плюралистических и мультикультурных принципах, а мусульманские общины имеют достаточно сильные позиции, что обусловлено имперским прошлым и высоким уровнем лояльности к инокультурным мигрантам. Важным условием британской миграционной политики является то, что ни один этнос не должен превышать $20 \%$ в общей численности мигрантов. После возрастания притока нелегалов и беженцев культурная и социальная интеграция осложнилась и стала чаще увязываться с включением мигрантов в экономику страны. Однако недостаточно активные меры по их социализации и интеграции в сферу занятости привели к появлению новых этнических анклавов, а ужесточение миграционной политики вызвало рост недовольства многих этнических групп, особенно из стран Содружества.

\section{Поиск новых подходов для взаимодействия и адаптации разных этносов}

В 2011 г. лидеры Франции, Германии, Великобритании заявили о провале политики мультикультурализма и попыток ассимилировать и интегрировать мигрантов. Толерантность как основа мультикультурализма сама по себе не сможет заставить принимающее общество быть толерантным к мигрантам и снять остроту межэтнических и межконфессиональных конфликтов. Несмотря на содействие включению мусульман-мигрантов в принимающий социум через различные курсы и программы, страны ЕС продолжают сталкиваться с проблемами концентрации этнических меньшинств в неблагополучных зонах и радикализации молодёжи. 
Неудачи в построении многокультурного общества связаны с самой концепцией мультикультурализма, воспроизводящей другие изолированные этнические общины даже при использовании разных стратегий поведения по отношению к мусульманам. Преобладающая часть мусульман не принимает культурные нормы, обычаи и традиции европейских стран, а продолжает жить по своим канонам, особенно молодёжь, которая менее образована и плохо трудоустроена. Наличие мусульманских диаспор осложняет взаимодействие с коренным на-селением, замедляет их адаптацию и интеграцию в странах EC.

Всё это свидетельствует о нарастании этнокультурной и конфессиональной неоднородности в европейских государствах, привнесении новых элементов в сложившуюся систему взаимосвязей коренного и иммигрантского населения. Новые поколения и потомки осевших мигрантов имеют новые культурные, религиозные и поведенческие особенности. А цивилиза-ционное и конфессиональное разнообразие в европейском обществе это не просто данность, а процесс формирования особой идентичности мусульман в Европе.

Ассимиляция и полноценная интеграция невозможна при нарастании цивилизационных противоречий и радикализации ислама на фоне экономического неравенства, высокого уровня безработицы у иммигрантской молодёжи и расслоения в обществе, где существуют две нации - титульная и второстепенная. Адекватная модель интеграции, отвечающей этнорелигиозному многообразию, и более прагматичный подход к этим проблемам, основанный на уважении языковых и культурно-конфессиональных различий, соблюдении общих политических и экономических принципов и равном доступе к правам и занятости, в странах ЕС пока отсутствуют.

В условиях роста миграции и обострения проблемы межконфессионального взаимодействия мигрантов с принимающим обществом выросло значение культурных аспектов их интеграции. Сегодня более уместно говорить об интеркультурализме, суть которого состоит в ориентации на собственную идентичность культурных групп и на межэтнический и межконфессиональный диалог для предотвращения конфликтов в европейском обществе, где уже существует культурное и религиозное разнообразие ${ }^{1}$. В странах ЕС наметился новый подход к интеграции мигрантов - социальная интеграция, которая строится на изучении истории, культуры, обычаев страны пребывания и на обучении языку. Это содействует не только социальной адаптации, но и повышает шансы мигрантов, в т.ч. мусульман, постепенно интегрироваться в европейское общество. Этот процесс будет достаточно длительным и не всегда успешным, т.к. конфликты и противоречия не только сохранятся, но и будут периодически нарастать из-за дальнейшего необратимого роста мусульманского населения.

\section{Список литературы}

Интеграция инокультурных мигрантов: перспективы интеркультурализма. Отв. редакторы Цапенко И.П., Гришин И.В. Москва, ИМЭМО РАН, 2018.

Чернобровкин И.П. Две модели интеграции мигрантов в ФРГ: сравнительный анализ. Социально-гуманитарные знания, №7, 2015. С. 63-70.

\section{References}

\footnotetext{
1 См., например: Интеграция инокультурных мигрантов: перспективы интеркультурализма. Отв. Редакторы Цапенко И.П., Гришин И.В. М., ИМЭМО РАН, 2018. С. 8-9.

Научно-аналитический вестник ИЕ РАН, 2019, №4
} 
Integraciya inokul'turnyh migrantov: perspektivy interkul'turalizma. Otv. redaktory Capenko I.P., Grishin I.V. Moskva, IMEMO RAN, 2018.

Chernobrovkin I.P. Dve modeli integracii migrantov v FRG: sravnitel'nyj analiz. Social'nogumanitarnye znaniya, №7, 2015. S. 63-70.

Europe Muslim Population in 2018. URL: http:www.muslimpopulation.com/Europe.

Europe's growing muslim population. Pew Research Center. 29.11.2017. P. 10-17. URL: http://pewresearch.org/fact/tank/2017/11/29/Europes-growing-muslim-population.

\section{Specific Features of Cultural and Religious varieties in the European Society}

Author. Olga Trofimova, Candidate of Sciences (Economics), Lead Researcher at the Center of European Studies, Primakov National Research Institute of World Economy and International Relations of Russian Academy of Sciences. Address: 23, Profsoyuznaya str., Moscow, Russia, 117997. E-mail: olgatrofimova53@mail.ru.

Abstract. The article treats interconnections between European society and muslim diasporas which have their own cultural and religious traditions and customs. The author analyses specific features of integrating policies of migrants in various EU countries, its islamisation, problems of fragmentation of the European society and new approaches to integration of Muslim migrants.

Key words: Integration of Muslim migrants, European Union, inter-ethnic cooperation and conflicts, national identity, Islam.

DOI: http://dx.doi.org/10.15211/vestnikieran42019104110 